\title{
What level of domestic government health expenditure should we aspire to for universal health coverage?
}

\author{
DI MCINTYRE* \\ Health Economics Unit, School of Public Health and Family Medicine, Faculty of Health Sciences, University of Cape \\ Town, Cape Town, South Africa \\ FILIP MEHEUS ${ }^{\mathrm{a}}$ \\ Health Economics Unit, School of Public Health and Family Medicine, Faculty of Health Sciences, University of Cape \\ Town, Cape Town, South Africa \\ JOHN-ARNE RØTTINGEN \\ Norwegian Institute of Public Health, Ministry of Health, Oslo, Norway \\ Department of Health Management and Health Economics, Institute of Health and Society, Faculty of Medicine, \\ University of Oslo, Norway \\ Department of Global Health and Population, Harvard T.H. Chan School of Public Health, Harvard University, \\ Cambridge, MA, USA
}

\begin{abstract}
Global discussions on universal health coverage (UHC) have focussed attention on the need for increased government funding for health care in many low- and middle-income countries. The objective of this paper is to explore potential targets for government spending on health to progress towards UHC. An explicit target for government expenditure on health care relative to gross domestic product (GDP) is a potentially powerful tool for holding governments to account in progressing to UHC, particularly in the context of UHC's inclusion in the Sustainable Development Goals. It is likely to be more influential than the Abuja target, which requires decreases in budget allocations to other sectors and is opposed by finance ministries for undermining their autonomy in making sectoral budget allocation decisions. International Monetary Fund and World Health Organisation data sets were used to analyse the relationship between government health expenditure and proxy indicators for the UHC goals of financial protection and access to quality health care, and triangulated with available country case studies estimating the resource requirements for a universal health system. Our analyses point towards a target of government spending on health of at least $5 \%$ of GDP for progressing towards UHC. This can be supplemented by
\end{abstract}

\footnotetext{
"Correspondence to: Professor Di McIntyre, Health Economics Unit, Department of Public Health and Family Medicine, University of Cape Town, Anzio Road, Observatory 7925, Cape Town, South Africa. Email: Diane.McIntyre@uct.ac.za

aPresent address: International Agency for Research on Cancer, World Health Organisation, 150 Cours Albert Thomas, 69372 Lyon, France.
} 
a per capita target of $\$ 86$ to promote universal access to primary care services in low-income countries.

Submitted 6 June 2016; revised 5 September 2016; accepted 3 November 2016

\section{Introduction}

There is a growing international focus on the need for adequate domestic government spending on a range of social services, including health care. The debate leading up to the adoption of the Sustainable Development Goals (SDGs) was particularly influential in this regard. As noted by the UN System Task Team on the Post-2015 UN Development Agenda "Ensuring people's rights to health and education, including through universal access to quality health and education services, is vital for inclusive social development" and requires investment to "close the gaps in human capabilities that help perpetuate inequalities and poverty across generations" (2012: 26). The Addis Ababa Agenda on Financing for Development was even more explicit, stating "We recognize that significant additional domestic public resources, supplemented by international assistance as appropriate, will be critical to realizing sustainable development and achieving the sustainable development goals" [United Nations (UN), 2015: para 22].

Universal health coverage (UHC) has been identified as one of the health-related SDGs. UHC calls for health systems in which everyone has access to the services they need (irrespective of whether such services are preventive, promotive, curative, rehabilitative or palliative), where these services are of adequate quality to be effective, and universal financial protection from the costs of using these services. The 2010 World Health Report unambiguously states that in order to move towards UHC, mandatory pre-payment financing mechanisms must form the core of domestic health care financing [World Health Organisation (WHO), 2010]. Mandatory pre-payment funding includes tax and other government revenue (e.g. royalties on the exploitation of mineral resources) and mandatory health insurance contributions [i.e. social health insurance (SHI) models], with the latter being frequently regarded as a form of dedicated health tax and counted as part of government expenditures in macroeconomic statistics. Recent research, using large cross-national panel data sets, confirms the importance of increased levels of public funding of health services (particularly increased tax funding) in improving countries' health status, the ultimate goal of universal coverage reforms (Moreno-Serra and Smith, 2015; Reeves et al., 2015).

This paper considers what level of public funding countries should aim for in order to move towards UHC. We focus specifically on domestic public funding, linked to an explicit value base about individual governments' responsibilities to make available domestic resources to the maximum extent possible to meet their health and other human rights' commitments to their citizens (Balakrishnan et al., 
2011). The basis for this is Article 2.1 of the International Covenant on Economic, Social and Cultural Rights (ICESCR), which asserts that: "Each State party to the present Covenant undertakes to take steps, individually and through international assistance and co-operation, especially economic and technical, to the maximum of its available resources, with a view to achieving progressively the full realization of the rights recognized in the present Covenant by all appropriate means, including particularly the adoption of legislative measures" (emphasis added).

While many low-income countries will continue to require external funding for health and other social services for the foreseeable future, such funds should supplement and be additional to domestically generated public funds (Farag et al., 2009). Hence, this paper focusses on individual country governments' obligation to generate domestic funding to provide 'maximum available resources' and considers potential targets for government spending on health that reflect this concept in order to move towards UHC.

\section{Potential quantitative targets for government spending on health care}

To date, targets related to the issue of how much should be spent on health care have generally fallen into one of two categories. Most often, an absolute per capita amount has been specified [Commission on Macroeconomics and Health (CMH), 2001; High-Level Taskforce (HLTF), 2009]. However, absolute targets have tended to focus on what is required to provide a limited number of health services rather than what is required to move towards UHC.

The second kind of target is a relative one, with the most well-known being the 'Abuja target', which called for African governments to devote at least $15 \%$ of total government spending to the health sector (Organisation of African Unity, 2001). Very few African countries have reached the Abuja target, or even made much progress towards reaching it (Govender et al., 2008). That is partly because ministries of finance object to a target that they regard as undermining their autonomy to make sectoral budget allocation decisions (Njora, 2010).

A drawback of this form of relative target is that calling for an increased share of government expenditure on the health sector implies that spending on other sectors, and at least their share, should decline, which could mean less expenditure on other social services. This, in turn, could adversely affect other social determinants of health. Furthermore, given the large degree of variability in government revenue and expenditure across individual countries, irrespective of the level of economic development [e.g. ranging from government expenditure of less than $13 \%$ to over $40 \%$ of gross domestic product (GDP) in low-income countries] (International Monetary Fund, 2012), it is problematic to set a target relative to the government budget since this, in itself, does not exert pressure on governments to ensure 'maximum available resources'.

An alternative relative target is to specify government spending on health relative to the total economy - namely, GDP. We argue that this is the most 
appropriate target in the context of UHC goals and the right to health for several reasons. This measure takes account of affordability within a specific country context as the health expenditure target is expressed relative to the country's level of economic activity. Also, unlike the Abuja target, it does not argue for more government spending on health at the expense of other social services. Instead it directs attention also to the need for overall government revenue and expenditure as a percentage of GDP to reach levels that are adequate to realise the rights contained in the ICESCR. Calling for an increase in government spending on health as a percentage of GDP does not imply a reduction in spending on other social services; rather it provides a basis to advocate for increasing both government resource mobilisation and spending on the full range of human rights and social determinants of health in situations where governments are not presently providing 'maximum available resources' (see Meheus and McIntyre, 2017 for discussion of how government resource mobilisation can be improved).

If progress is to be made towards UHC, increased government funding (which includes all forms of mandatory pre-payment funding) will be necessary. Reliance on out-of-pocket (OOP) payments should be reduced in order to provide financial protection, as well as on voluntary private health insurance as neither financing mechanism contributes to equitable progress to UHC (WHO, 2010). We would, therefore, argue that the key target from a UHC perspective is government expenditure on health as a percentage of GDP. The main challenge remains: What percentage of GDP should a government spend on health services in order to meet the 'maximum available resource' to pursue UHC objectives?

\section{Government health expenditure as a percentage of GDP: What should the target level be?}

Our approach to identify an appropriate relative target is to draw on as wide a range of evidence as possible, and to triangulate between these different sources of evidence and determine if they all point to a common figure. We first undertook our own international comparative analysis to explore the relationship between government health expenditure as a percentage of GDP and indicators of relevance to UHC (see Box 1). As indicated above, key elements of UHC include financial protection from the costs of ill health and access to and use of needed health services within a country.

Reducing the reliance on OOP payments for health care is important for financial protection, as demonstrated by Xu et al. (2003) in their study of 59 countries: 'A $1 \%$ increase in the proportion of total health expenditure provided by out-of-pocket payments is associated with an average increase in the proportion of households facing catastrophic payments of $2.2 \%$. Figure 1 shows that there is a strong correlation between government spending on health services as a percentage of GDP and the share of total health care expenditure funded from OOP payments (correlation 
Box 1. Methodological approach to identifying an appropriate target

For our primary data analysis, an international comparative approach was used: the relationship between government health expenditure as a percentage of GDP (the target indicator) and a number of indicators related to UHC goals was assessed for all countries for which data are available.

The first step was to identify indicators that are of relevance from a UHC perspective. These indicators were selected on the basis of the definition of UHC (financial risk protection and access to needed care), and importantly their availability for most countries in the world. Recently, a range of possible indicators of health service coverage has been suggested (Boerma et al., 2014), but the majority of these indicators are not presently available for most countries. We have used the indicators that are available.

The relevant indicators for all available countries were extracted from International Monetary Fund and World Health Organisation data sets, and were plotted graphically (each UHC-related indicator was plotted separately against government health expenditure as a percentage of GDP) and a line fitted to the data. The correlation of each variable with the government health expenditure variable was also calculated. While inevitably there is some dispersion around the line, on the basis of acceptable correlation levels, we explored what government health expenditure target was implied by the country data. This was achieved by identifying a generally accepted target for the UHCrelated variable (e.g. out-of-pocket payments being $20 \%$ or less of total health expenditure, $90 \%$ immunisation coverage, etc.), and determining the level of government health expenditure as a percentage of GDP that intersected with this target on the fitted line.

We then triangulated these estimates with available country case studies estimating the resource requirements for a universal health system through modelling of detailed health service cost and utilisation data.

coefficient $=-0.62$ ); the greater the level of government health spending as a percentage of GDP, the lower the share of OOP payments in total health spending.

The 2010 World Health Report stated that: "It is only when direct payments fall to $15-20 \%$ of total health expenditures that the incidence of financial catastrophe and impoverishment falls to negligible levels" (WHO, 2010: xiv). If a vertical line is drawn from the fitted line in Figure 1 at the point where OOP payments are $20 \%$ of total health expenditure, it will meet the horizontal axis near the $6 \%$ of GDP point. Thus, this indicator suggests that a target of public spending of about $6 \%$ of GDP should be set if OOP payments are not to exceed $20 \%$ of the total amount spent on health care.

The other component of UHC is access to and use of needed health services for all within a country. The availability of data on this component relative to the need for health services is limited. Two indicators that are available - deliveries performed by a skilled birth attendant and child immunisation coverage rates do not provide a good indication of overall health service coverage as they refer 


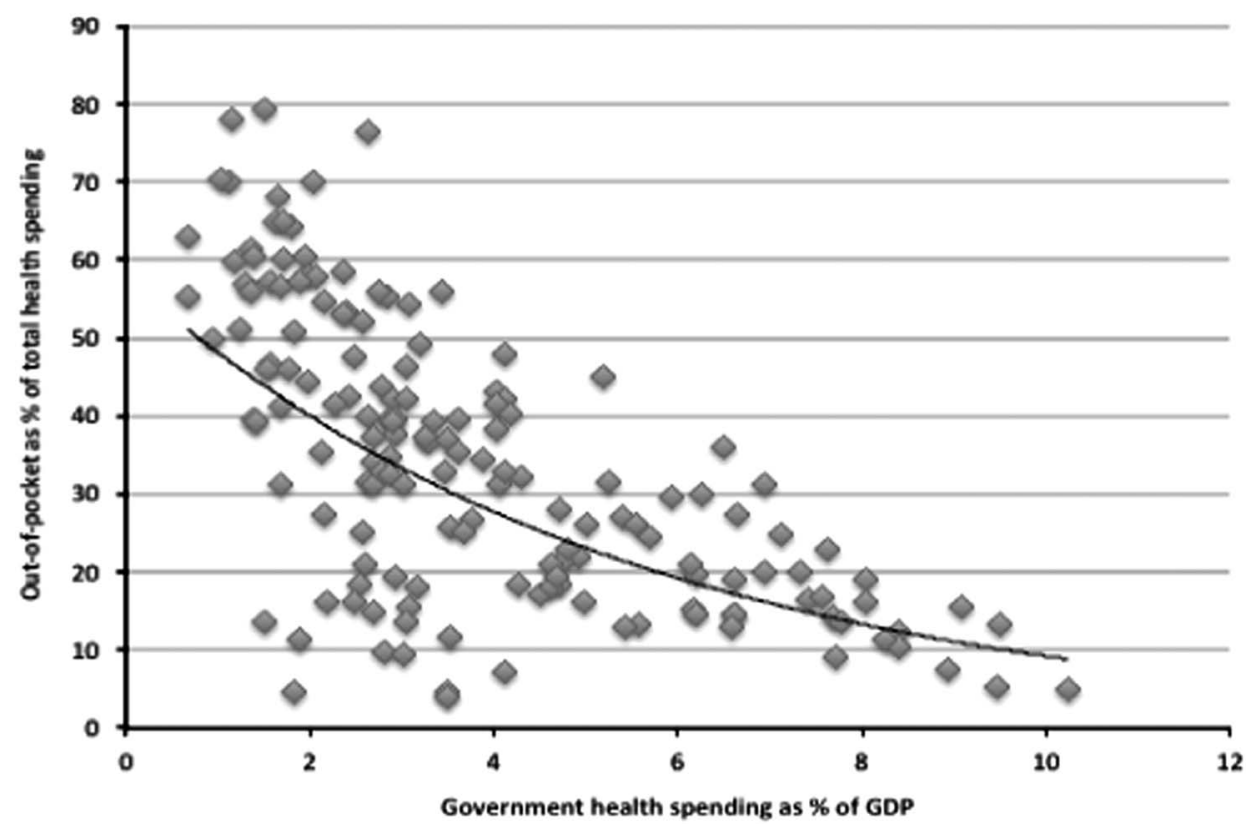

Figure 1. Relationship between government health spending and reliance on out-of-pocket payments (2011).

Source: Updated from McIntyre and Kutzin (2011) using data from http://apps.who.int/nha/ database/DataExplorer.aspx?ws $=1 \& \mathrm{~d}=1$

Note: GDP $=$ gross domestic product.

only to two types of maternal and child health $(\mathrm{MCH})$ service, both of which have been singled out for significant improvement in the context of the Millennium Development Goals (MDGs). Nevertheless, analysis of both coverage indicators suggests that government spending on health of more than $5 \%$ of GDP will achieve a very conservative target of $90 \%$ coverage (which is the coverage target adopted by the CMH, 2001) (data not shown).

An indicator of the availability dimension of access to health services that is widely used and for which the WHO has set a target is that of health workers per 10,000 population. The WHO's Service Availability and Readiness Assessment project recommends a minimum of 23 core medical professionals/10,000 population, which it defines as 'physicians, non-physician clinicians, registered nurses, and midwives' (WHO, 2012). Figure 2 indicates that, based on the relationship between government expenditure on health and core health workforce indicators (correlation coefficient $=0.53$ ), government expenditure should be around $3 \%$ of GDP to reach the minimum target of 23 core medical professionals/10,000 population and over $5 \%$ of GDP in order to achieve the current global average of 44/10,000 population. While the current average for low-income and lower-middle-income countries (LMICs) is only 10 and 27/10,000 population, respectively, the average for upper-middle-income countries is 67 and for high-income countries 107. 


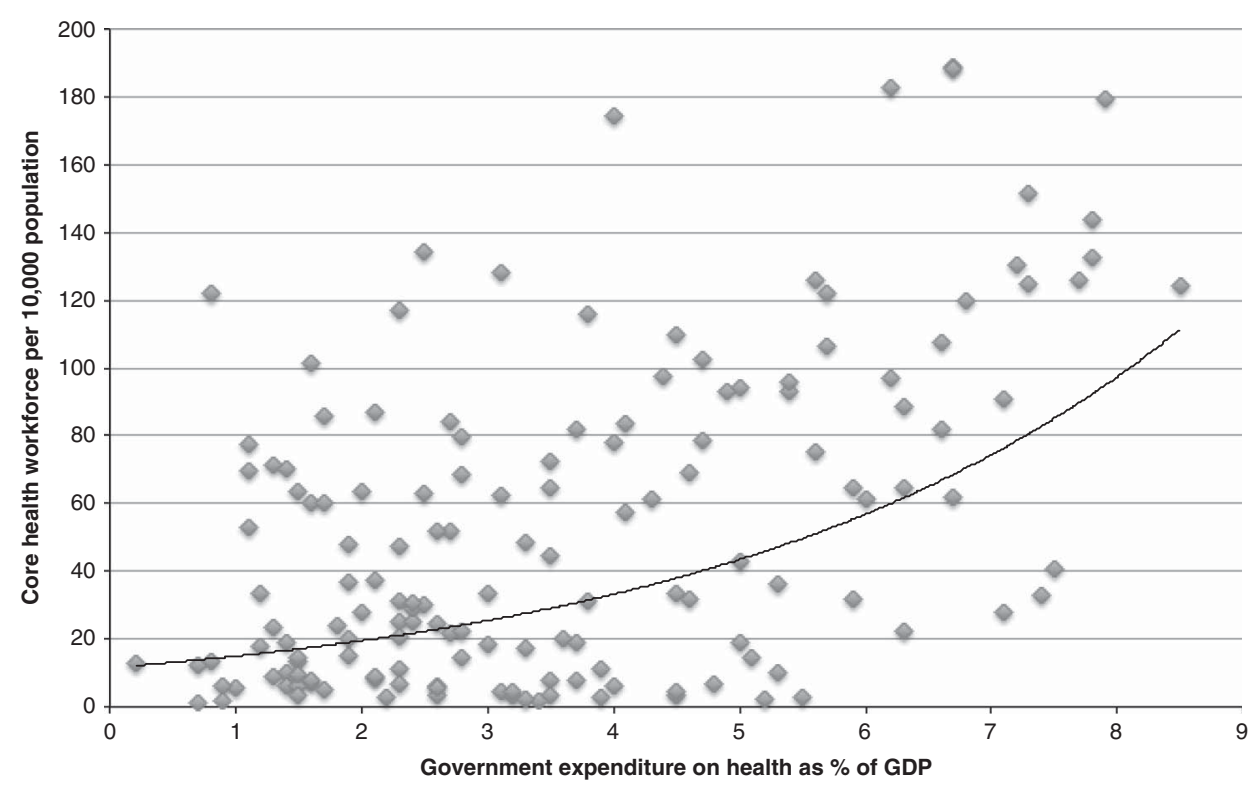

Figure 2. Relationship between availability of core health workforce and government health spending (2009).

Source: Adapted from WHO (2011).

Note: GDP = gross domestic product.

All the above analyses suggest that a target of government expenditure of at least $5 \%$ of GDP is an appropriate one. We then compared this figure with evidence from secondary sources. Savedoff (2007) argues that the most appropriate way of estimating the level of government resourcing needed to achieve a particular goal (in this case UHC), is to assess health service requirements and to cost these. While these costing exercises are often carried out to estimate the financial resource requirements of specific programmes (e.g. HIV/AIDS or $\mathrm{MCH}$ services), a few studies have examined the cost of more comprehensive preventative and curative health services, or the cost of achieving UHC.

Overall, studies projecting the financial resource requirements to achieve universal health systems using detailed health service cost data and modelling techniques indicate that public health expenditure should exceed $5 \%$ of GDP by 1-2 percentage points. For instance, in South Africa, McIntyre and Ataguba (2012) found that the least costly universal coverage scenario required government expenditure on health to increase to $6.4 \%$ of GDP, while in Tanzania, Borghi et al. (2012) estimated that in order to achieve universal coverage by 2025 , public health service delivery costs (i.e. not all costs) would represent $4.3 \%$ of GDP. Financial feasibility studies of SHI carried out by the WHO using SimIns ${ }^{1}$ showed public expenditure projections (including Ministry of Health and SHI

1 See http://www.who.int/health_financing/tools/simins/en/ 
Table 1 Summary of analyses for relative target

Indicator/type of analysis

Public health spending as \% GDP implied by analysis

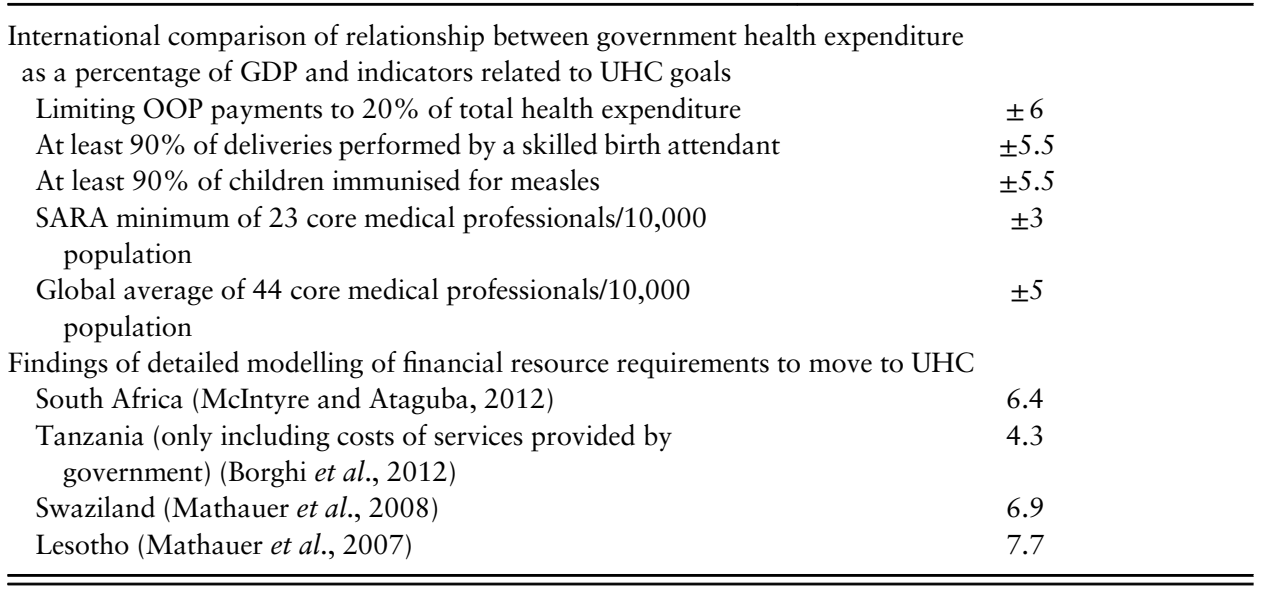

Note: GDP = gross domestic product; UHC $=$ universal health coverage; $\mathrm{OOP}=$ out-of-pocket; SARA = Service Availability and Readiness Assessment.

expenditure) ranging between 6.9 and $7.7 \%$ of GDP in Swaziland and Lesotho, respectively (Mathauer et al., 2007; Mathauer et al., 2008). ${ }^{2}$

The final source of evidence we considered was analyses undertaken for the 2010 World Health Report, which documented actual levels of mandatory pre-payment funding for health in countries that are considered as having universal health systems. "Those countries whose entire populations have access to a set of services usually have relatively high levels of [mandatory] pooled funds - in the order of 5-6\% of gross domestic product" (WHO, 2010: xv).

While each of the above methods for estimating resource requirements for moving towards UHC has its deficiencies, when taken together as a total body of evidence (see Table 1) a strong case for a target for government health expenditure of at least $5 \%$ of GDP can be argued for from a UHC perspective. This is also in line with the current global average of $5.1 \%$ of GDP. While a few countries, most notably Thailand, have made considerable progress to UHC at government expenditure levels of less than $5 \%$ of GDP, this is by far an exception and requires very high levels of efficiency that are difficult to achieve. Establishing a target of $5 \%$ of GDP for government spending on health does not mean that we should not do everything possible to use resources efficiently.

2 The WHO studies provided estimates on health expenditure to cover $100 \%$ of the population by 2018. The calculations of public health expenditure as a percentage of GDP were done by the authors using GDP projections (constant prices) from the IMF World Economic Outlook database (http://www.imf.org/ external/ns/cs.aspx?id=28; accessed on 28 May 2014). 
The proposed target is appropriate for countries across economic development levels and will be applicable over time: for low-income countries, this target will allow for progress towards universal primary health care (PHC) services; as GDP increases so the $5 \%$ will translate into an increase in absolute financial resources and the ability to expand the range of health services covered. A key criticism of the MDGs was that they were only applicable to low- and middle-income countries; the era of the SDGs demands targets that are universal and globally applicable (Scott and Lucci, 2015). While it may take longer for low-income countries to meet this target, a growing number of low- and middle-income countries are demonstrating that government revenue and expenditure levels relative to GDP can be increased dramatically with measures to improve tax compliance and revenue collection administration, ensuring public revenue gains from the exploitation of natural resources, increasing tax rates where these are low and introducing innovative public financing mechanisms (see Meheus and McIntyre, 2017). The target is one that countries can work systematically to achieve. Countries should be judged not by whether or not they have achieved this target, but by how much progress they have made towards this target over a particular period of time.

\section{Should this be supplemented with a per capita target?}

Given the variation in per capita GDP across countries, the relative target of $5 \%$ of GDP translates into very different amounts in absolute monetary terms (across low-income countries, from as little as $\$ 13 /$ person in Burundi and Malawi to nearly $\$ 60$ in Kyrgyzstan, and up to $\$ 190$ in LMICs). Even if low-income countries achieved the target of $5 \%$ of GDP in government spending on health, would this be sufficient to deliver core PHC services universally? It is evident that most low-income countries, and some LMICs, will continue to require external assistance for the foreseeable future. An absolute per capita target would, therefore, be a useful complement to the relative target for domestic government expenditure as a percentage of GDP.

An absolute per capita target can be developed by costing a set of core PHC services. At present, there are two main sources of estimates on the resource requirements that LMICs have to meet in order to provide such services:

- The CMH (2001), and

- The HLTF (2009) on Innovative International Financing for Health Systems.

The $\mathrm{CMH}$ focussed on a very limited set of services dealing with AIDS, tuberculosis and malaria (ATM diseases) and key MCH services. Although both the CMH and the HLTF estimates included various costs of scaling up health services, the HLTF examined a wider range of services than did the CMH. Besides MDG-related services, it also included health promotion interventions and essential drugs for chronic diseases, some cancers, neglected tropical diseases, mental health and general care (Taskforce on Innovative International Financing 
for Health Systems, 2009). Thus, the HLTF estimates approximate a more comprehensive range of PHC services. Both studies drew on demographic, epidemiological and costing data from a wide range of low-income countries.

The CMH estimated that by 2015 , the per capita resource requirements in lowincome countries would total $\$ 38$ (expressed in 2002 dollar terms), while the HLTF put that figure at $\$ 54$ (expressed in 2005 dollar terms) for more comprehensive services. We updated these estimates to 2012 terms based on inflation rates and changes in exchange rates since 2002 and 2005, respectively. Expressed in 2012 dollar terms, the CMH estimate is equivalent to $\$ 71$ and that of the HLTF $\$ 86 .^{3}$

In our view, it would be appropriate to use $\$ 86$ as the estimate of per capita resource requirements for providing core PHC services in low-income countries. The basis for this is that there is growing emphasis on all countries promoting universal access to at least primary level services that not only tackle $\mathrm{MCH}$ and the ATM diseases but also provide interventions for those suffering from noncommunicable diseases, mental health problems and other conditions beyond the current MDG focus. The HLTF estimate includes the cost of medicines for this broader range of diseases and services as well as the costs related to expanding facility and equipment infrastructure, increasing staffing levels and other means of strengthening health systems. Though stopping short of a fully comprehensive set of PHC services, it is unlikely to be far off the mark. However, this will only be the case if the $\$ 86$ is devoted fully to PHC services (and not, e.g. spent on high-cost tertiary services), and if these limited resources are used efficiently with the aim to deliver quality services. This can be promoted through ensuring that there is strategic purchasing of health services (RESYST, 2014).

Even if all countries reached the relative target of $5 \%$ of GDP, no low-income countries and only $60 \%$ of LMICs would be spending above the absolute target of $\$ 86$ per capita. This highlights the need for external support to secure the needed health care in countries which even at their 'maximum available resources' cannot meet this absolute target alone through domestic resources. However, in the context of findings that international funding often simply substitutes for, or displaces, domestic government funding for health services (Farag et al., 2009), the combination of these two targets can contribute to ensuring that international funds are truly additional to domestic public funds.

\section{Conclusion}

Our analyses of international data sets, and review of published estimates of resource requirements to move towards universal health systems, all point

3 We further updated these estimates to 2015 and found that the average remained at $\$ 71$ for the $\mathrm{CMH}$ estimate and $\$ 86$ for HLTF due to variable inflation rates (with rates in some countries being negative in certain years) and variable exchange rate changes across the countries included in the CMH and HLTF calculations. 
towards a relative target of government expenditure on health, funded from domestically mobilised resources, of at least $5 \%$ of GDP. While this may be aspirational for low- and middle-income countries that are currently far from this target, we believe it is achievable for all countries in the longer term. Other papers in this special issue consider how domestic government revenue can be increased so that this target can be achieved in support of moving towards UHC (Eloivano and Evans, 2017; McCoy et al., 2017; Meheus and McIntyre, 2017). The Addis Ababa Agenda (UN, 2015) is unambiguous in its call for each government to pursue improvements in domestic public resources to fund the SDGs, and explores ways of creating an enabling international environment for this.

This proposed target is appropriate for countries across economic development levels; as GDP increases so will the 5\% translate into an increase in absolute financial resources and the ability to expand the range of health services covered. However, a specific percentage of GDP obviously translates into a lower absolute amount in low-income countries than in middle- or high-income countries. It is within this context that a per capita monetary target has a role to play; domestic government spending of $5 \%$ of GDP will not even ensure universal access to primary care services in any low-income countries. Although absolute per capita targets have deficiencies, particularly that a set monetary amount will buy very different quantities of services in different countries due to differences in health worker wages and other input prices, it can play an important role in advocating for domestic government and international assistance funds that are truly additional to at least move towards universal primary care services.

Low- and middle-income countries will not make substantial progress towards universal health systems, and to realising the full range of economic, social and cultural rights, unless governments make concerted efforts to maximise their 'available resources'. An explicit target for government expenditure on health services relative to GDP is a potentially powerful tool for holding governments to account in terms of these rights.

\section{Acknowledgements}

This research was undertaken to contribute to the Chatham House Working Group on Sustainable Health Financing. The authors are grateful to members of the Working Group for comments on this research.

\section{Financial Support}

This work is based on research supported by the South African Research Chairs Initiative of the Department of Science and Technology and National Research Foundation (NRF) of South Africa and the RESYST research consortium funded by UKaid from the Department of International Development. Any opinion, 
finding and conclusion or recommendation expressed in this material is that of the authors and the NRF and UKaid do not accept any liability in this regard. The study sponsor was not involved in the study design and collection, analysis and interpretation of data, or the writing of the article or the decision to submit it for publication. The authors were independent from study sponsors.

\section{References}

Balakrishnan, R., D. Elson, J. Heintz and N. Lusiani (2011), Maximum Available Resources and Human Rights, NJ: Center for Women's Global Leadership, Rutgers, New Brunswick, NJ.

Boerma, T., C. AbouZahr, D. Evans and T. Evans (2014), 'Monitoring intervention coverage in the context of universal health coverage', PLoS Med, 11(9): e1001728.

Borghi, J., G. Mtei and M. Ally (2012), 'Modelling the implications of moving towards universal coverage in Tanzania', Health Policy and Planning, 27(Supplement 1): i88-i100.

Commission on Macroeconomics and Health (CMH) (2001), 'Macroeconomics and Health: Investing in Health for Economic Development', Report of the Commission on Macroeconomics and Health, World Health Organisation, Geneva.

Eloivano, R. and D. Evans (2017), 'Raising more domestic money for health: prospects for low and middle income countries', Health Economics, Policy and Law, 12(2): 139-157.

Farag, M., A. K. Nandakumar, S. S. Wallack, G. Gaumer and D. Hodgkin (2009), 'Does funding from donors displace government spending for health in developing countries?', Health Affairs, 28(4): 1045-1055.

Govender, V., D. McIntyre and R. Loewenson (2008), 'Progress Towards the Abuja Target for Government Spending on Health Care in East and Southern Africa'. EQUINET Discussion Paper No. 60, Regional Network for Equity in Health in Southern Africa, Harare.

High-Level Taskforce (HLTF) (2009), 'Constraints to Scaling Up and Costs. High Level Taskforce (HLTF) on Innovative International Financing for Health Systems’. Working Group 1 Technical Report, World Health Organisation, Geneva.

International Monetary Fund (2012), World Economic Outlook, October 2012, Washington, DC: IMF.

Mathauer, I., O. Doetinchem, J. Kirigia and G. Carrin (2007), Feasibility Assessment and Financial Projection Results for a Social Health Insurance Scheme in Lesotho: Exploring Possible Options, Geneva: World Health Organization.

Mathauer, I., L. Musango, G. Carrin and K. Mthethwa (2008), Feasibility Assessment and Financial Projection Results for a Social Health Insurance Scheme in Swaziland: Exploring Possible Options, Geneva: World Health Organization.

McCoy, D., S. Chigudu and T. Tillmann (2017), 'Framing the tax and health nexus: a neglected aspect of public health concern', Health Economics, Policy and Law, 12(2): 179-194.

McIntyre, D. and J. Kutzin (2011), 'Revenue collection and pooling arrangements in health system financing', in R. Smith and K. Hanson (eds) Health Systems in Low-and Middle-Income Countries, Oxford: Oxford University Press, 77-101.

McIntyre, D. and J. Ataguba (2012), 'Modelling the affordability and distributional implications of future health care financing options in South Africa', Health Policy and Planning, 27(Supplement 1): i101-i112.

Meheus, F. and D. McIntyre (2017), 'Fiscal space for domestic funding of health and other social services', Health Economics, Policy and Law, 12(2): 159-177. 
Moreno-Serra, R. and P. Smith (2015), 'Broader health coverage is good for the nation's health: evidence from country level panel data', Journal of the Royal Statistical Society, 178(1): 101-124.

Njora, G. (2010), 'African finance ministers dismiss development declarations'. FAHAMU, http://pambazuka.org/en/category/comment/63894 [25 May 2010].

Organisation of African Unity (2001), Abuja Declaration on HIV/AIDS, Tuberculosis and Other Related Infectious Diseases, Addis Ababa: Organisation of African Unity.

Reeves, R., Y. Gourtsoyannis, S. Basu, D. McCoy, M. McKee and D. Stuckler (2015), 'Financing universal health coverage - effects of alternative tax structures on public health systems: cross-national modelling in 89 low-income and middle-income countries', Lancet, 386(9990): 274-280.

RESYST (2014), 'What is Strategic Purchasing for Health?', Resilient and Responsive Health Systems, London School of Hygiene and Tropical Medicine, London, http://resyst.lshtm.ac.uk/sites/resyst.lshtm.ac.uk/files/docs/reseources/Purchasing\%20brief.pdf [13 October 2014].

Savedoff, W. D. (2007), 'What should a country spend on health care?', Health Affairs, 26(4): 962-970.

Scott, A. and P. Lucci (2015), 'Universality and ambition in the post-2015 development agenda: a comparison of global and national targets', Journal of International Development, 27(6): 752-775.

Taskforce on Innovative International Financing for Health Systems (2009), More Money for Health, and More Health for the Money: Report of the Taskforce, Geneva: International Health Partnership.

United Nations (UN) (2015), Report of the Third International Conference on Financing for Development, New York: United Nations.

UN System Task Team on the Post-2015 UN Development Agenda (2012), Realizing the Future we Want for All: Report to the Secretary-General, New York: United Nations.

World Health Organisation (WHO) (2010), 'Health Systems Financing: The Path to Universal Coverage'. World Health Report 2010, WHO, Geneva.

World Health Organisation (WHO) (2011), World Health Statistics, 2011, Geneva: World Health Organisation.

World Health Organisation (WHO) (2012), Measuring Service Availability and Readiness: A Health Facility Assessment Methodology for Monitoring Health System Strengthening. Service Availability Indicators, Geneva: WHO.

Xu, K., D. B. Evans, K. Kawabata, R. Zeramdini, J. Klavus and C. J. L. Murray (2003), 'Household catastrophic health expenditure: a multicountry analysis', Lancet, 362(9378): 111-117. 